\title{
UNA VIDA DE PELÍCULA Reflexiones en torno a las nuevas presentaciones de la intimidad
}

\author{
Por Florencia Varela
}

En este artículo, Florencia Varela analiza cómo el yo se ha convertido en el protagonista privilegiado de las narraciones de la televisión, el cine y la web. Reality shows, redes sociales electrónicas - como Facebook o Myspace- y directores de cine que presentan su autobiografía, son prácticas autorreferenciales que significan, entre otras cosas, nuevas formas de construcción del sí mismo. Relatos de ficción que se presentan como situaciones reales; momentos íntimos o subjetivos que se vuelven materia de exhibición y de espectáculo. Recuperando la mirada de autores clásicos y nuevos, el artículo problematiza un tema fundamental para pensar (y pensarnos) en la comunicación.

El año pasado, la revista Rolling Stone realizó una reseña literaria de Buena leche, el libro de la polémica blogger argentina Lola Copacabana. En ella se plantearon las "sensaciones de la blogoesfera; impresiones y caprichos de esta chica de veintitantos con relatos de aventuras de la vida cotidiana: clases en la Facultad de Derecho, su vida junto a su pequeña hija, amores que van y vienen...."

El yo parece ser el protagonista favorito de las narraciones que circulan en diferentes ámbitos de la esfera cultural. En el cine, la web o la televisión proliferan prácticas que algunos autores conciben como confesionales o autorreferenciales. Las televisiones de todo el planeta incorporan contenidos centrados en las lógicas del reality o en la intimidad de la vida cotidiana; un formato televisivo válido tanto para personas no mediáticas como para personajes reconocidos. Aunque lo que se intenta es retratar la cara más corriente y los huecos más íntimos del protagonista de turno, en la mayoría de los casos el resultado no pasa de ser un relato ficcionalizado, es decir construido en función de los parámetros mediáticos exigidos. De esta forma, las historias de vida televisadas presentan muchas veces personajes coherentes con historias muy dramáticas, muy felices o muy interesantes, como si la vida no estuviera cargada de contradicciones, momentos diversos, monótonos o intensos. Y, lo que es más problemático, se presentan como situaciones reales puras.

Advertimos una situación similar en la web, con herramientas como los blogs, Facebook o Myspace, entre otras también prolíficas en relatos acerca del yo. 


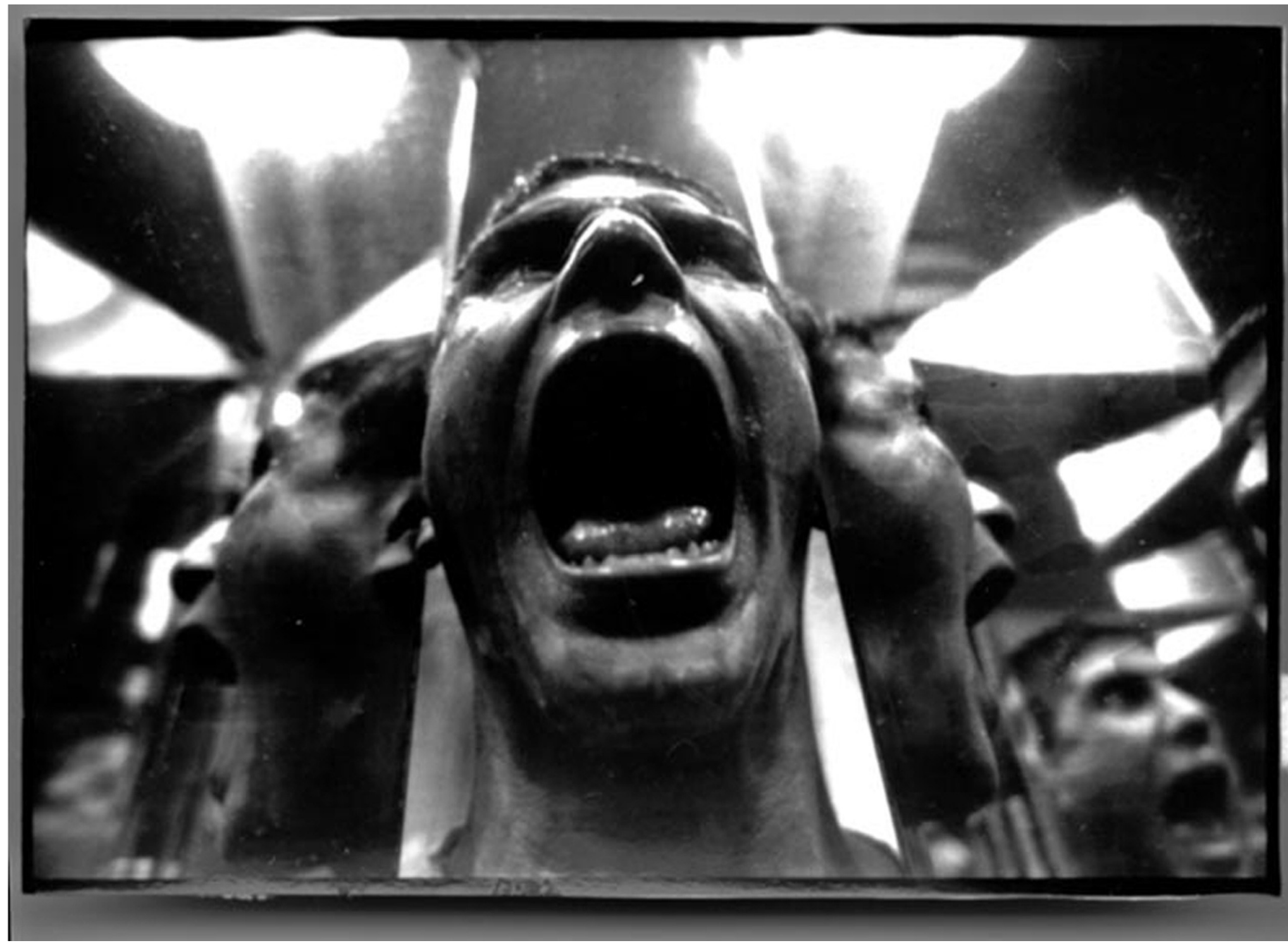

Estas plataformas de Internet permiten que hagamos partícipes a los integrantes de nuestra red de amigos o de contactos, del discurrir de nuestra vida cotidiana o de los eventos destacados en nuestro ámbito personal y doméstico. La investigadora Paula Sibilia califica a este tipo de prácticas autorreferenciales como las nuevas formas de construcción del sí mismo. Con ello, Sibilia se refiere a la tendencia por la cual la intimidad y los relatos personales son, cada vez más, material de exhibición. ${ }^{2}$ Una situación que se constata cada día en la cara más exhibicionista de los blogs, los videos de You Tube o los distintos reality shows. En el cine, por otra parte, Sibilia cita la película 33 (2002) del brasileño Kiko Goifman, en la que el director, próximo a cumplir treinta y tres años, decidió filmar un viaje de treinta y tres días en el que se proponía encontrar a su madre biológica.
¿A qué responde este interés por los relatos del yo? Podemos calificar estos relatos que hacen referencia a la vida de una persona como biográficos o autobiográficos, cuando el autor habla sobre sí mismo. Si bien es cierto que no todas estas narraciones e imágenes autorreferenciales pueden ser concebidas bajo la estricta definición del género autobiográfico, ${ }^{3}$ por remitir éste fundamentalmente a un tipo específico de género literario, no cabe dudas de que las actuales prácticas autorreferenciales constituyen una "versión extendida de las formulaciones autobiográficas convencionales", más afín a las potencialidades de los nuevos medios, según explica Cuevas Álvarez en su estudio sobre el cine doméstico. ${ }^{4}$ En este sentido, si nos ceñimos a la definición aportada por un estudioso de estos temas, el francés Philippe Lejeune en la que establece que la autobiografía consiste en una
$2::$

Paula Sibila: La intimidad como espectáculo, Buenos Aires, Fondo de Cultura Económica, 2008, p. 27 y 28.

3::

Para profundizar en los origenes de la autobiografia remitirse al texto de F. E. Puertas Moya: Los orígenes de la escritura autobiográfica. Género Modernidad, SERVA - Universidad de La Rioja, Logroño, 2004. 4::

Esta es la idea que desarrolla $\mathrm{E}$. Cuevas Álvarez en "Del cine doméstico al autobiográfico: caminos de ida y vuelta". Cineastas frente al espejo G. Martin (ed.), Madrid, 2008, pp. 101 y sig.

Foto P. P.

Autorretrato 
5:

Cito aquí a F. J., Hernández:

"Escritura autobiográfica y destinatario", en Thélème: Revista complutense de estudios franceses, № 11, 1997, pp. 427438. Disponible en la Red http://www.ucm.es/BUCM/revista s/fll/11399368/articulos/THEL979 7120427A.PDF [Fecha de Consulta: 21/09/2007]

M. Zambrano: La confesión: género literario, Mondadori, Madrid, 1988, p. 20

P. Sibilia: La intimidad como espectáculo, o. cit., 2008, p. 60.

Roland Barthes: Roland Barthes por Roland Barthes, Barcelona Paidós, 2004.

R. Barthes en el frontispicio:

Roland Barthes por Roland Barthes, Barcelona, Kairós 1978 cfr. por P. Jay: El ser y el texto. La autobiografía, del Romanticismo a la Posmodernidad. (Representaciones textuales de yo, de Wordsworth a Barthes) Madrid, Megazul, 1993, p. 25

Ph, Lejeune: El pacto autobiográfico y otros estudios, Megazul-Endymion, Madrid, 1994 coincidencia entre autor, narrador y protagonista, advertiremos en la creciente importancia que han adquirido este tipo de narrativas en las prácticas actuales. Prácticas que se ubican entre la realidad y la ficción, como más adelante veremos.

De este modo, los actuales discursos autorreferenciales se vinculan con las prácticas autobiográficas de antaño, materializados en autores como Stendhal, Constant y Michelet o con las de García Márquez y Victoria Ocampo, por ejemplo. Un modo de vida, al decir de Lejeune, que estará asociado con el cultivo de la vida interior y con el autoconocimiento. La necesidad de indagar sobre el si mismo constituye entonces una de las claves que responde a nuestra pregunta inicial. Pero, ¿qué es lo que lleva a un autor a confesar a otros sus verdades intimas? Existe un fuerte impulso hacia los demás en aquello que lo lleva a realizar tales confesiones. Como Francisco Javier Hernández señala, distintos autores se han ocupado de demostrar que el discurso autobiográfico es aquel en el que incide con más intensidad la presencia de un interlocutor. ${ }^{5}$ Por ello María Zambrano reconoció en la confesión una búsqueda del otro, "hasta el simple iay! cuenta con un interlocutor posible. El lenguaje, aún el más irracional, el llanto mismo, nace ante un posible oyente que lo recoja”. ${ }^{6}$ Desde esta perspectiva entonces, a la exposición de la propia vida, en la imagen o en el texto, del propio cuerpo o del propio entorno, le subyace siempre la pregunta: ¿Quién soy yo?

\section{El yo: ese otro ficticio}

Si hay algo que está claro es que si las televisiones apuestan por productos reality, o las editoriales convierten en libros las diversas experiencias de la generación blog, es porque hay un público tan ávido de producir estos relatos como de consumirlos. En este sentido, la condición de autenticidad de estas narraciones, que viene dada por el hecho de pertenecer a las experiencias de un individuo real, ejerce un extraordinario efecto de fascinación. ¿Cómo se explica este poderoso atractivo? Para Lejeune la respuesta se halla en la recepción, puesto que el relato de la existencia de otro nos devuelve la mirada sobre la nuestra propia.

No obstante, Sibilia observa que entre estos relatos contemporáneos autorreferenciales, de 'no ficción', encontramos personajes-narradores-autores estilizados, dignos de protagonizar una saga mediática en la que también se estilizan las experiencias vitales y la cotidianidad. Como un modo de adaptar "los principales acontecimientos de su vida a las exigencias de la cámara", ${ }^{7}$ lo que resultaría entonces en una autobiografía ficcionalizada. Es decir un yo que al fin y al cabo termina por no coincidir con el autor referente.

Pero los textos autobiográficos y las narraciones autorreferenciales en general, siempre implican la ficcionalización del yo, que se construyen desde un acto de reinvención del sí mismo. A esto dedica Roland Barthes su emprendimiento autobiográfico, o más bien antiautobiográfico, concretado en su clásica obra Roland Barthes por Roland Barthes: "No hay biografía más que de la vida improductiva”, escribe el autor; “en cuanto produzco, en cuanto escribo, es el Texto mismo el que me desposesiona (afortunadamente) de mi duración narrativa". ${ }^{8}$ Construido sobre la base de fragmentos, a través de los cuales no adivinamos si pertenecen a su pasado o a su presente, el mismo Barthes advierte que todo cuanto allí se diga "debe ser considerado como si lo dijera un personaje de novela". ${ }^{9}$ Lo que Barthes deja planteado entonces es que el yo textual es un otro ficticio.

Por ello, Lejeune explica que no es requisito de este género coincidir con la verdad de los acontecimientos, porque no consiste en el hecho de que alguien diga la verdad sobre su vida, sino en que alguien diga que lo hará. ${ }^{10}$ Esta es la diferencia con otros relatos, como la novela por ejemplo. De este modo se establece un "pacto autobiográfico" con el lector, en el que éste asumirá que está frente a un acto confesional. ${ }^{11}$ Es un pacto que 
se establece en la recepción, ya que, según Lejeune, la actitud del lector no es la misma que si está frente a un “pacto de ficción”. En este caso la historia deja al lector mucho más libre, mientras que en el pacto autobiográfico el compromiso es mayor necesariamente, dado que en él proyecta su propio reflejo.

En relación con esta falta de coincidencia entre el sujeto real y el sujeto de la representación autobiográfica, el teórico y crítico español Pozuelo Yvancos sostiene que "también hay una práctica actual de ficcionalización de toda ocurrencia del yo, con la crisis de la idea de sujeto del discurso, que ha alimentado la modernidad y acentuado la posmodernidad". "Yvancos vincula esta crisis de la identidad y del sujeto con la tradición de la filosofía de Nietzsche, para quien el sujeto "no es algo dado, sino algo añadido, inventado y proyectado sobre lo que hay".

Esto podría explicar en parte los modos contemporáneos de presentación de la subjetividad, correspondidos por una forma distinta de ser y estar en el mundo, con una noción del yo que ya no se concibe como privado ni habita tan solo en nuestro interior. En su texto El yo saturado, Kenneth Gergen afirma que el yo -como eje que nos sostiene- se esfuma en el entramado de relaciones en el que está inserto, pues éste sólo puede existir en relación con el otro. ${ }^{14}$ En este sentido, para Paul Jay lo que Barthes intenta demostrar es “que el 'yo' es algo siempre hecho pedazos, diseminado, descentrado y -al menos en un textosiempre “ficción'". ${ }^{15}$ Existe entonces un cambio en el yo que narra con respecto de aquellos hábitos autobiográficos de antaño, que no se reduce únicamente al cambio de formato: del libro o del diario a las pantallas, por ejemplo.

Pero aunque en principio la adaptación a los nuevos medios pueda parecernos un pasaje sin mayores consecuencias, en este desplazamiento pueden advertirse importantes secuelas. Las autobiografías actuales no solamente presentan un grado de exhibicionismo diferente, sino que además están protagonizadas por un yo que no es simplemente un narrador de su vida, "aunque sea la trillada y cada vez más festejada epopeya del hombre común, del antihéroe o del hombre ordinario".16 Ahora el autor además de estampar su existencia hace de ella una vida de película, y por eso la exhibe. Así cambian, fundamentalmente, los modos de construcción del sí mismo, "se transforma la subjetividad que se construye en esos géneros autobiográficos”.

Me mediatizo, luego existo

Uno de los fenómenos que llama la atención es la frecuencia con que estas prácticas autorreferenciales se configuran a través de imágenes: imágenes del sí mismo o imágenes del entorno cercano y doméstico del autor. Esta es una de las atracciones de las herramientas web como Facebook, Fotolog o Myspace, que ofrecen una amplia plataforma para subir fotos y videos, o armar perfiles de los autores con imágenes y textos. También los blogs o You Tube cuentan entre sus aplicaciones con posibilidades similares. Esta es además la idea básica de la lógica del reality televisivo, bien definida por la imagen icónica del más famoso de ellos: un ojo combinado con un objetivo. Y así podríamos enumerar distintos ejemplos en los que se constata la predilección por el reflejo de sí mismo.

De este modo, aunque el género autobiográfico sea el marco referente de las prácticas confesionales actuales, se advierte asimismo una predilección exacerbada por la propia imagen. A este respecto resulta interesante señalar que existe en el ámbito artístico una situación que puede leerse como correlato de estos nuevos modos de construcción del sí mismo. Recientemente, la revista de arte y cultura Exit Book dedicó uno de sus últimos números al análisis de las propuestas artísticas autorreferenciales, acompañadas además por la generación de distintas narraciones biográficas y, sobre todo, autobiográficas y testimoniales. En su
Florencia Varela:: (Montevideo, 1976). Es doctora en Filosofía, área de Estética y Teoría del Arte por la Universidad de Salamanca, y licenciada en Comunicación Social por la Universidad Católica del Uruguay. En 2008 y 2009 fue becaria de investigación para el Estudio en

Fracaso Escolar del Centro de Análisis Sociales de la Universidad de Salamanca y la Fundación La Caixa. Fue docente titular de Comunicación Visual I en la Licenciatura en Comunicación Social en la Universidad Católica del

Uruguay, entre otras materias. Coordinó en 2003 la producción de la campaña presidencial en Guatemala, con la consultora internacional LCB-Marketing Político, y trabajó previamente en varios proyectos de educación, marketing y producción audiovisual.

$12::$

J. M. Pozuelo Yvancos: De la autobiografía. Teoría y estilos, Barcelona, Editora Diagonal, 2006, p. 21.

13::

lbíd., pp. 35 y 36 .

$14::$

Ver: K. J. Gergen: El yo saturado Barcelona, Paidós, 1992.

15::

P. Jay, El sery el texto..., o. cit., 1993 , p. 208.

$16::$

Cito aqui a Sibilia, La intimidad como espectáculo, o. cit., 2008, pp. 61 y sig. 
R. Olivares: "Editorial. Todo 17 mí mismo", Exit Book, no 11 septiembre 2009

18:

"A partir del Renacimiento podemos hablar de una conciencia subjetiva, de una saturación de la obra de arte con rasgos derivados de la personalidad del artista", E. Kris

O. Kurz: La leyenda del artisto Madrid, Cátedra, 1982, p. 108; cfr., por M. Rodríguez: "La subjetividad en el arte: la figura del genio" en S. Arango, et Escritos sobre historia y teoria 1 : ciudad - arte - arquitectura Universidad Nacional de Colombia, 2003, p. 115

R. Olivares: en Exit Book o. cit., 2009

P. Solans: "Del espejo a la pantalla. Derivas de la identidad", en D. Hernández Sánchez (Ed.) Arte, Cuerpo, tecnología Salamanca, 2003, p. 137. lbíd., p. 139 22:

Véase: J. A. Agúndez García: "El ojo del elefante", en Primer generación. Arte e imagen en movimiento [1963-1986] Madrid, Museo Nacional Centro de Arte Reina Sofía, 2006, p. 340 editorial, Rosa Olivares subrayaba: "La realidad, hoy en día, es que el artista crea una gran parte de su trabajo en torno a sí mismo, y cuenta su propia historia y experiencias de una forma casi obsesiva". ${ }^{17}$ Una tendencia que, ciertamente, no es novedosa, pues ya en el Renacimiento el mito de genialidad artística nacido en la mitología griega llevó a Vasari a elaborar las biografías de Cimabue y Giotto. ${ }^{18}$

Sin embargo, aunque la producción de textos acerca de la vida y la persona del artista, impulsada por el halo aurático que rodeaba su figura, no sea un fenómeno reciente, sí parece haber adquirido en los últimos tiempos una morfología diferente. Porque tal como explica Olivares, en la actualidad, artistas como Francesca Woodman, Cindy Sherman, John Coplans o Sophie Calle, entre otros, son con frecuencia los principales protagonistas de sus obras. Biografías físicas, explica, que llevan a afirmar que "hoy la obra de un gran número de artistas traza claramente una autobiografía visual antes aún que una biografía literaria". ${ }^{19}$

Desde una óptica lacaniana, Piedad Solans afirma que el reflejo del sí mismo ha sido materia de obsesión de la cultura occidental en la Época Moderna desde el Renacimiento, la Ilustración y el Romanticismo, en tanto "superficie imaginaria, lugar sensible, donde se confronta el problema del conocimiento, la identidad y la realidad". ${ }^{20}$ Pero en esta superficie sensible, el cuerpo es proyectado de forma tal que adquiere una imagen mediante la que se conforma a la vez como lo otro. Se descubre, al mismo tiempo, la experiencia paradójica de "la imposibilidad de la mirada de tocarse a sí misma, de mostrarse si no es en la alteridad”, y que implica "ese juego de despliegues entre la mismidad y la otredad que se contempla (...) la imposibilidad del sujeto de revelarse a sí mismo si no es idealmente a través del otro y de lo otro"."

En la actualidad, entonces, concurrimos a una proliferación de estas “autobiografías visuales" en prácticas que no se restringen únicamente al ámbito artístico, sino que parecen canalizar gran parte de los modos contemporáneos de subjetividad y sociabilidad. Prácticas que se inscriben dentro de un proceso más amplio de exhibición. Como si el yo solamente adquiriese consistencia cuando se ve reflejado en las pantallas, como afirma Sibilia. Ahora bien, aunque todas estas prácticas pudieran converger en la interrogante acerca del yo, existe sin embargo una diferencia substancial. Mientras algunas narraciones autobiográfica se fraguan en conexión con lo que Sibilia entiende como una realidad más fundamental y profunda, otras lo hacen respecto de una realidad más epidérmica, de sustancia 'enrarecida' explica la autora, presentada por los medios de comunicación.

El problema que surge no solamente tiene que ver con la forma que adquiere esa realidad mediática, sino con ese desplazamiento en los modos de construcción del si mismo al que hacíamos referencia. En el primero de los casos basta con mencionar que los parámetros mediáticos, como ya no es misterio para nadie, no se definen únicamente por la riqueza creativa del medio sino también, y en gran medida, en función de intereses de rentabilidad. Esto condiciona el modo en que se presenta la realidad mediática que, a grandes rasgos, tiene las siguientes características: es veloz, debido a los tiempos restringidos por la publicidad y por el público; intensa, debido a la disputa por retener a la audiencia y su atención; coherente y ordenada, debido a su condición masiva. Todas estas características buscan presentar una realidad digerible. Contra esta realidad digerible estuvieron dirigidas muchas de las obras del artista Wolf Wostell, quien proponía sus televisiones indigestas con las cuales atacar la limpia y clara realidad mediática. ${ }^{22}$

Por otro lado, en lo que respecta a los modos de construcción del sí mismo, éstos parecen surgir desde las relaciones mediáticas más que desde las relaciones del individuo consigo mismo. Esto último es lo que 


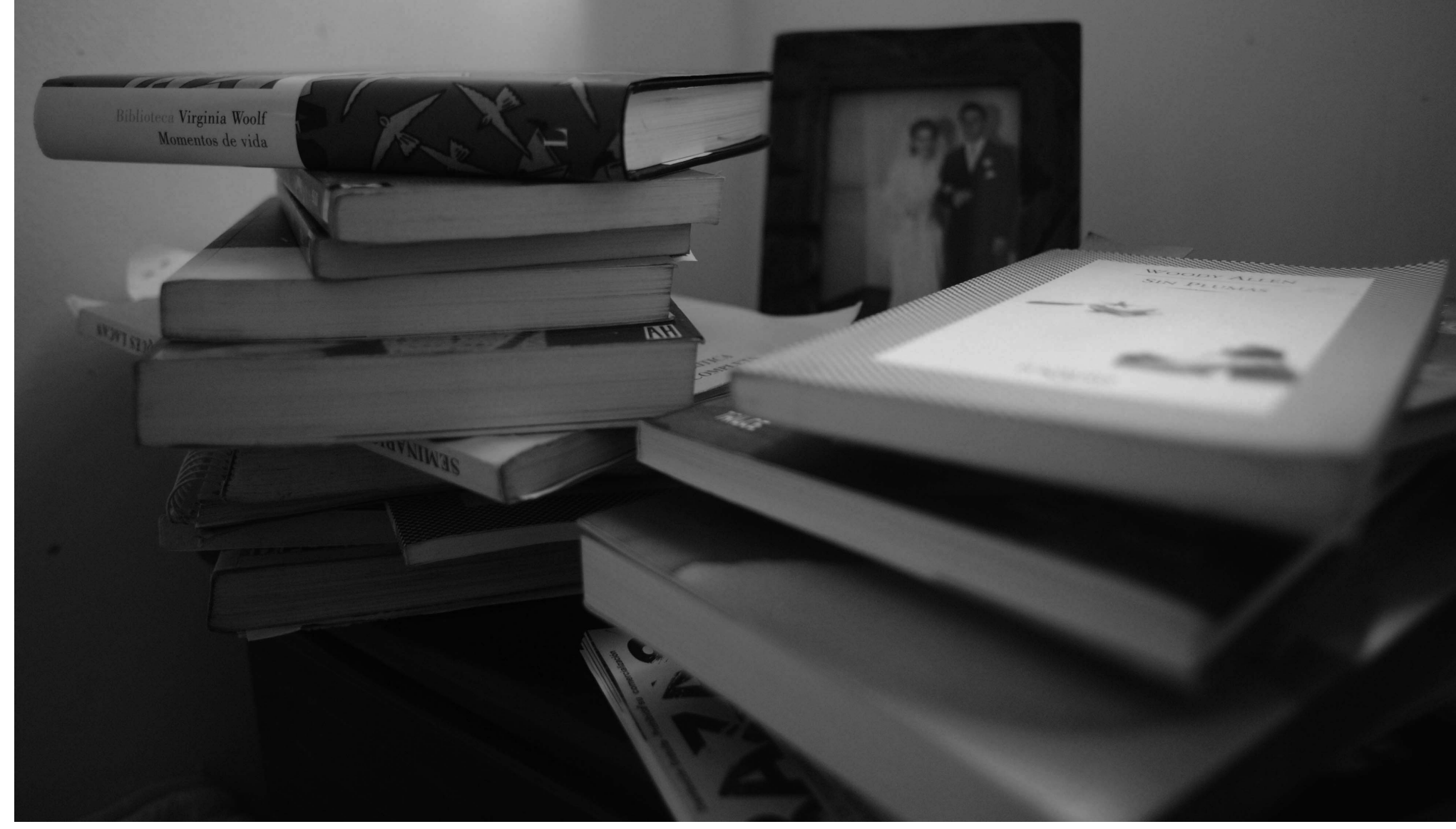

Foucault concibió como ética del sujeto, a través de la cual se lleva adelante un proceso de subjetivación que hace que el individuo encuentre su propia forma de vivir, su modo personal de ser y estar en el mundo. Esto es, la forma por la cual "se constituye uno como sujeto de sus actos". ${ }^{23}$ Pero cuando este proceso de subjetivación está condicionado más por los modelos mediáticos que por la relación conmigo mismo, este modo particular de sentirme y habitar el mundo se descubre más bien como un modo básicamente masificado.

"Tienen look característico, casi homogéneo: flequillo, colores...", así califica Javier Sinay a los floggers en su crónica editada en la Rolling Stone de Argentina. Una fiebre flog de la cual Agustina Vivero, argentina de 17 años, de apodo Cumbio, es su principal protagonista. Los datos recogidos hasta el año 2008 señalan que su fotolog recibía treinta mil page views al día. ${ }^{24} \mathrm{La}$ caracterización que hace el cronista de los floggers resulta muy significativa: se produce una especie de inversión en la que el individuo ya no se ve reflejado en la pantalla, sino que él mismo se convierte en el reflejo de los medios masivos. El sujeto acude a la realidad mediática con el fin de adquirir consistencia.

\section{Realidad, ¿espejo de la ficción?}

Para Sibilia, gran parte de las prácticas autorreferenciales actuales que no se inscriben entre los confines de la actividad artística, recurren a los imaginarios ficcionales "para tejer las narraciones de la vida cotidiana". Como si la incertidumbre acerca de la situación del yo, que Ester Díaz señala como propia de la Posmodernidad, ${ }^{25}$ generase la necesidad de aprehender fórmulas mediáticas. Una situación que según Sibilia se explica o se corresponde con el deseo de acceder a una experiencia aumentada e intensa de lo real, "cuyo grado de eficacia se mide, paradójicamente, con estándares mediáticos". ${ }^{26}$ Aunque las razones que explican esta circunstancia son muy complejas y merecerían un ensayo aparte, podemos hallar una de las claves en aquel aspecto cruel y doloroso con que Clément Rosset concibe lo real. Aquello irremediable e inapelable que nos impide
23::

M. Foucault: Historia de la sexualidad, Vol. 3, Madrid, Siglo XXI, 1987, p. 42.

$24::$

J. Sinay: "Fiebre flog", Rolling Stone, Argentina, marzo 2008 25::

E. Diaz: Posmodernidad, Buenos Aires, Biblos, 2005, p. 37 26::

P. Sibilia: La intimidad como espectáculo, o. cit., 2008, p. 223

Foto P. P. 
E. Díaz: La filosofía de Miche

Foucault, Buenos Aires, Biblos, 2003 , p. 177

S. i ek: El sublime objeto de /a ideología, México, Siglo XX

1992 , p. 24

P. Sibila: La intimidad como espectáculo, o. cit., 2008, p. 252

Véase: C. Rosset: Lo real y su doble. Ensayo sobre la ilusión

Barcelona, Tusquets, 1993.

Cito aquí a M. Perniola: El arte y

su sombra, Madrid, Cátedra, 2002, pp. 9 y sig. atenuar su rigor. La realidad cruda es la realidad en sí misma, "apenas accesible, por eso es extraña, por eso extraña”, nos dice Domingo Hernández Sánchez, quien -recurriendo a una cita de Guy Debord- añade enfáticamente: "Y el espectáculo es precisamente la inversión de lo real, o, de otro modo, "el núcleo del irrealismo de la sociedad real'". ${ }^{27}$

Casos como el de Lola Copacabana, que afirma ser igual a su personaje y que asegura que no existe en su vida nada inconfesable, confirman de alguna manera la tesis acerca de la espectacularización de la intimidad. Una intimidad, claro está, ficcionalizada, que ya no se construye en la interioridad del sujeto, como en las prácticas de autoconocimiento descritas por Foucault, ni en su relación íntima con los otros, sino que se produce desde el exterior.

Sibilia concibe estas subjetividades, que repiten de forma indiscriminada modelos mediáticos, como personalidades 'alterdirigidas'. Y, fundamentalmente, alterdirigidas por los medios de comunicación. Porque si antes el sujeto tenía tiempo para internalizar las fuerzas que lo constituían, para plegarse y desde allí reinventarse, de un tiempo a esta parte el sujeto reproduce subjetividades, es decir, acciones, modos de ser y modos de estar propios de la ficción. Y las reproduce de forma cada vez más exacta e inmediata: mayor definición y a tiempo real parecen ser las consignas generacionales que mejor describen cierto aspecto del actual clima de época. Consignas que, aplicadas a las tecnologías, sugieren una gran ventaja, mientras que no ocurre lo mismo si se aplican de forma indiscriminada a los sujetos.

Esto es cierto, al menos desde el pensamiento de Foucault, para quien las subjetivaciones, en tanto modos que constituyen el sujeto, no solamente responden a interiorizaciones del afuera e interactúan con lo proveniente desde el exterior, sino que además “se constituyen también en las relaciones del hombre consigo mismo". ${ }^{28}$ Como sostiene el autor Slavoj i ek, para Foucault "cada sujeto, sin apoyo alguno de normas universales, ha de construir su propio modo de autodominio, ha de armonizar el antagonismo de poderes en su interior, inventarse, por así decirlo, producirse como sujeto, encontrar su propio y particular arte de vivir". 29

Pero en la sociedad espectacularizada, la relación con el si mismo parece estar sufriendo un desplazamiento. La pregunta acerca de quién soy yo lleva cada día más a un zapping mediático con una amplia oferta de paquetes estilísticos e identitarios, en lugar de permitir una inmersión en las aguas profundas y amorfas del si mismo. Y es que la realidad mediática en general exhibe realidades digeribles, y no vidas indigestas. Así, recurrir a la realidad mediática resulta más atractivo. En este sentido, Paula Sibilia no duda en afirmar que "ya no se le pide más a la ficción que recurra a lo real para ganar verosimilitud y consistencia", ahora, en cambio, es la realidad la que "precisa adquirir consistencia desesperadamente" a través de la ficcionalización. ${ }^{30}$

En este contexto, la moción por relatos de ficción que celebren la creatividad, así como también la inspiración y la reflexión, se hacen urgentes. Porque lo real cruel de Rosset por ser inaccesible, como el núcleo duro lacaniano, solamente puede ser descifrado haciéndolo entrar en un proceso de significación. ${ }^{31}$ Tal como explica Mario Perniola, lo real planteado por Rosset mediante la noción de idiocia, "sería pues idiota precisamente porque no existe más que para sí mismo y es incapaz de aparecer de modo distinto a como es"."

Una de las más importantes conclusiones de este análisis es que, mientras en los procesos de construcción de la subjetividad las personas acudan a estas supuestas prácticas de 'no ficción', los medios cargan con una gran responsabilidad.:. 